\title{
Model of Activity Development to Promote Students' Morality in Primary School
}

\author{
Phrakrusoponpattaravet (Ittipol Padhãniko) ${ }^{1}$, Phrasuwanmahaphuthaphibal (Ho Subhaddo) ${ }^{2}$, \\ Phrakrukosolpariyattayanukij (Tharueti Virojano) ${ }^{3}$, Phramaha Yannawat Thitavaddhano ${ }^{4}$ \\ ${ }^{1,2,3,4}$ Faculty of Education, Mahachulalongkornrajavidyalaya University, Thailand \\ 10odwatsaymai@gmail.com, ${ }^{2}$ howattrimitr@gmail.com, ${ }^{3}$ konkuandee@gmail.com, ${ }^{4}$ yannawat.bud@mcu.ac.th
}

\begin{abstract}
The purpose of this research was to propose a model of activity development to promote students' morality in primary schools under the Office of Primary Education Service Areas. Mixed methods research was used for the research design. The target group were 17 key informants and 24 school administrators whereas 400 school teachers were used for data collection. Content analysis was used for qualitative analysis, and quantitative data were analyzed by using percentage statistics, frequency, mean, and standard deviation. Results showed that students' morality was developed through 5 aspects consisted of 1) Sufficiency, 2) Gratitude, 3) Integrity, 4) Responsibility, and 5) Moral ideology, and analyzed results were shown at a high level in all aspects. A model of activity development to promote students' morality in primary schools composed of 1) Curriculum, 2) Learning objectives, 3) Teaching plan preparation, 4) Teaching and learning activities, and 5) Assessment. The developed model focused on 4 important aspects which were 1) Ethic, promote 5 virtues for students, which are sufficiency, gratitude, integrity, accountability, and moral ideology by using the model to develop activities to promote morality of students. 2) Activity Development, it was focused on teaching and learning activities, including curriculum, learning objectives, teaching plans, teaching and learning activities, and assessment. 3) Support, support the development of activities to promote morality of students under cooperation between administrators, teachers, school board members, monks, parents, and communities. 4) Students, students will receive the most from the activity development promote the morality.
\end{abstract}

Keywords

Activity Development, Students' Morality, Primary School

Article Received: 10 August 2020, Revised: 25 October 2020, Accepted: 18 November 2020

\section{Introduction}

The world today is the age of information technology with the evolution and potential of information technology. Thus, the knowledge that existed quickly spread. The advantage of each country depends on the ability to take advantage of that knowledge developing people to have high potential and quality to seek and make use of knowledge is therefore the role and function of development. Development management to develop people to have quality is essential. It must be a quality development in order to fully develop the potential that exists in people. People who know to think critically known to solve problems be creative Learn to learn by yourself, able to adapt to keep pace with the rapid changes, having ethics, morality, self-reliance and able to live happily in society according to the provisions of the Kingdom of Thailand. (Office of the Basic Education Commission, 2010: 2) [1].

Morality and ethics are valuable things that Thai ancestors have preserved along with the Thai nation since ancient times. Nowadays, in the age of globalization morality and good ethics of Thai people are about to be ignored and cause many social problems especially students and youth, who are the future of the nation, receive a foreign culture that flows into the boom in science and technology. The lack of consideration and the lack of being a good role model for people in the consumerist era made it worrisome. If there is no action to stop these problems, it will have a profound impact on Thai society. (Commission on Education, Religion, Art and Culture, 2007: 10) [2], in the management of learning in educational institutions that emphasize the morality of learners. Ethics in accordance with the provisions of the Constitution of the Kingdom of Thailand 2007, it is considered that the school administrators are the leaders in teaching and learning management to develop students' quality to be a person who is keen on learning continuously, able to think, solve problems, love human beings love nature and environment as well as being a broad vision and a neutral mind in teaching and learning for students. Teachers are expected to improve teaching skills and experiences in accordance with learners' abilities, interests, needs and attitudes with a student-centered emphasis emphasis is placed on the learning process to be able to learn to be for continuous learning and to be used in the creation and preparation of human resources to provide the country with suitable quality and consistent with the sustainable economic and social development of the country. In which school administrators have to formulate strategies by changing the learning process for the learners to seek knowledge and learn by themselves more. Administrators have to accelerate the systematic and continuous development of teachers to become persons with appropriate potential to provide the development, training and development of the youth of the nation as a human resource that is of importance to the nation.

Therefore, the essential element or tool to help develop children and youth is the moral and ethical principles that create a moral conscience, the inner quality is admiration, praise while the act of evil surely brings pain virtuousness. It is an international matching criterion such as not killing animals. They do not persecute, steal, do not misconduct in sexual relations. It is the condition of doing good deeds, 
which is the suitability to the events that occur, and able to make decisions and solve problems appropriately according to the principles of morality and ethics that can be classified, able to teach, train to follow the standards of correct behavior, with a consciousness. Responsible for good and sanctioned having a good mind, character, and intentions or intentions (Phraphrombandit (Prayoon Dhammajitto), 2013: 25-26) [3].

The nature of that virtue, the delicate things in the minds of each person cannot be measured or controlled by law or any regulations, but can control their own consciousness. Those who have a moral conscience can forbid their own wrong thoughts and can deter actions that are not worthy and able to control oneself to behave only in good things that being a truly good person, because a virtuous person has to have the following main elements: 1) being real, 2) knowing, controlling, 3) self-tolerant and patient, 4) knowing, loving, generous, 5) having compassion pity wants others to be free from suffering, 6) to appreciate when others are good, and 7) to be indifferent. Virtue is something that promotes and develops students to be a complete human being, both in body and character of that virtue. It is a delicate thing in each person's mind. It cannot be measured or controlled by any law or regulation, but can control their own consciousness. Those who have a conscience able to forbid their own wrong thoughts and can deter unreasonable actions and able to control oneself to behave only in good deeds, therefore will be regarded as a good person indeed, because the virtuous person must have the following main elements: 1) being real, 2) knowing, controlling, 3) tolerant and patient, 4) knowing, loving, generous, 5) having compassion, others are free from suffering, 6) appreciate when others are good, and 7) know how to ignore such virtues. It is something that fosters and develops students to be a complete human being, both physical and human. Valuable to society in the future students must be trained and training both physically and mentally as Phutthaphot that those who have trained themselves well considered to be a complete human being (Phra Maha Chakrit Rachasri, 2008: 226) [4].

The school, as a development institution expected by society, has a role to play in nurturing students to be qualified people to belong to society create a sense of responsibility and have a reasonable understanding of the principles of truth. Therefore, the school must have the aim of transferring knowledge, develop intelligence to learners along with moral and ethical development, and culture of living able to live happily with others which is in line with the government that has organized a moral school project OBEC in order to inherit the science of the king At His Majesty King Bhumibol Adulyadej His Majesty's royal orders "Help build good people for the country" and bestow three principles on teachers and students that "Let teachers love children and children love teachers, have teachers teach children to be kind to their peers not to compete, but to compete against themselves and to have children who are good at learning to help teach their peers at a later time, have the teacher organize activities for students to challenge together in order to see the value of unity "in order to lead the royal order come to practice concrete. It aims to instill in the administrators, teachers, students and educational personnel to be cultivated in 5 virtues: 1) sufficiency, 2) gratitude, 3) honesty, 4) responsibility, and 5) moral ideology (Office of the Basic Education Commission, 2017: a) [5].

OBEC moral school project is an operation to carry on the royal wishes, following in the footsteps of His Majesty King Bhumibol Adulyadej. According to the wishes of His Majesty King Rama 10, the Minister of Education has assigned the Deputy Minister of Education implement policies under the National Strategic Framework on Morality in collaboration with the Office of the Basic Education Commission as the person responsible for providing education for the majority of the country's youth to be quality citizens. It is also responsible for the provision of education for all youths to have knowledge, ability, be good, smart and happy according to the policy of the Ministry of Education.

Establish a "Moral School Project OBEC" to develop schools at the basic education level, make students, teachers, administrators and educational personnel to realize, understand and have a rational thinking process to absorb the value of virtue naturally, and create a sense of conscience as well as create a network of moral organizations community by coordinating cooperation from agencies and organizations that work on morality clearly that model of moral school. It's simple and easy to do. It is a low investment but very profitable, and can actually change the behavior of students. The moral school principals can be applied to schools of all religions, does not have a monopoly on any religion like a universal virtue. This will help "decrease" unwanted behavior in school and promote "more" desirable behavior, which is a sustainable development of youth, parents and communities.

Therefore, the researcher is interested in studying the patterns of development of a model of activity development to promote students' morality in primary schools under the Office of Primary Education Service Areas which is a school that operates teaching at the elementary level from school development management by combining the development of model and the development of virtue principles to enhance knowledge and competence moral to such students as the researcher has the opportunity to look at teaching students. Therefore, wishes to study the status of moral promotion that elementary school students are likely to develop student behavior as a moral partner and how to develop such moral to be a permanent virtue for students in order to build up the youth virtue which will bring happiness and prosperity to Thai society in the future.

\section{Research Objectives}

The purpose of this research was to propose a model of activity development to promote students' morality in primary schools under the Office of Primary Education Service Areas.

\section{Research Method}

Mixed methods research was used for the research design. The target group were 17 key informants and 24 school administrators whereas 400 school teachers were used for data collection. Content analysis was used for qualitative analysis, and quantitative data were analyzed by using 
descriptive statistics consisted of percentage statistics, frequency, mean, and standard deviation.

\section{Research Findings}

Results of the study of the development condition of student's moral promotion activities of students in schools under the Primary Educational Service Area Office. The level of opinions on the development of moral promotion activities of students, and 50 items for schools under the Primary Education Service Area Office consisted of 1) sufficiency, 2) appreciation, 3) honesty, 4) responsibility, 5) moral ideology found that teachers' opinions towards development of moral promotion activities for students. For schools under the Primary Educational Service Area Office, the overall level was at the high level while each aspect was at the high level in all aspects. Results of the study, development model, moral promotion activities of students for schools under the Primary Educational Service Area Office.

Development model for moral promotion activities of students for schools under the Primary Educational Service Area Office, it is the development of teaching and learning activities that teachers or teachers teach at the elementary school level, consisting of 1) curriculum education, 2) determination of learning objectives, 3) the lesson plan preparation, 4) the teaching and learning activities, 5) the evaluation and evaluation of the development of moral promotion activities. It is to promote the organization of teaching and learning activities, inserting morality and ethics of students, and organizing activities to promote goodness for students. The results of presentation of the development model for moral promotion activities of students for schools under the Primary Educational Service Area Office Development model for moral promotion activities of students to achieve results. There will be 3 main focus areas: 1) the number of students who have been developed to have more desirable behaviors in school, 2) More participation from the beginning is the study of the curriculum, the purpose of setting Learning, teaching plan, teaching and teaching activities and measuring and evaluating learning results, 3) the school instills five virtues: sufficiency, gratitude, honesty, responsibility, moral ideology, using the development model for moral promotion activities of students.

\section{Discussions}

Development of moral promotion activities for students 50 items for schools under the Primary Education Service Area Office consisted of 1) sufficiency, 2) appreciation, 3) honesty, 4) responsibility, 5) moral ideology found that teachers' opinions towards development of moral promotion activities for students for schools under the Primary Educational Service Area Office, overall, it was at a high level which is in line with the research of Ka Chanyiwa (2017) [6] has researched on "A model for promoting morality in students in basic educational establishments under the office Narathiwat Primary Educational Service Area 1 "The research results showed that current conditions in development promote morality to students in basic educational institutions under the office. The overall level of primary education in Narathiwat Province was at the high level. Basic educational institutions affiliated with the office Narathiwat Primary Educational Service Area 1 consists of 5 elements: 1) Behavior is a good role model for teachers of virtue, virtue; 2) moral development through the teachings of Islam and Buddhism together. It focuses on the students' kindness, kindness, patience and forgiveness; 3) Using the curriculum to develop students to adhere to and act according to virtue and virtue for a peaceful coexistence; 4) Organizing activities related to traditions or religious ceremonies in order to deter unwholesome thoughts and actions, and it is the practice of being a giver, such as forgiveness and known to share knowledge, goodness and the fifth component; 5) measuring and evaluating results covering knowledge, skills and attitudes. of learners, parents and other stakeholders, and to use the assessment results in the development of teaching and learning for assessing the feasibility of implementing the promoting morality to students in basic educational institutions under the office Narathiwat Primary Educational Service Area 1 was used. In the basic educational institutions under the office Narathiwat Primary Educational Service Area 1 overall at the most level and also related to Nonglak Jaisalad's research (2010), [7], that studied the moral enhancement model of Thai higher education institution students. It was found that the moral enhancement elements of students of Thai higher education institutions consisted of 8 elements, be a good example of a moral and moral teacher, organizing a participatory teaching and learning process insertion in teaching and learning of all courses. A general education course designation in the curriculum Organizing extra-curricular activities creating a good environment in higher education institutions, promoting arts and culture and adhering to democracy, and organizing creative and integrative activities as for the creation of a moral building model moral values of students of Thai higher education institutions 1) the role of the teacher has 3 components: being a good model of morality, morality of the teacher, organizing a participatory teaching and learning process; 2) the role of the administrators of higher education institutions consisted of 5 components, namely the formulation of educational courses. General in the course creating a good environment in higher education institutions, organizing extra curricular activities, promoting arts and culture and adhering to democracy promoting the organization of creative integrative activities for the evaluation of the moral reinforcement model of students. Thai higher education institutions, which the administrators of higher education institutions holding administrative positions in the faculty have an opinion consistent that the model is suitable. There is a high level of possibilities and benefits. From the study of related documents, it can be concluded that the moral development can be carried out by various methods, namely teaching according to the curriculum. There should be a course that teaches about morality directly by giving knowledge understanding of the subject content a lesson plan is organized suitable teaching curriculum. In addition, all courses should be taught in conjunction with moral content that can integration with daily use. 2) Activities, course-based activities, co-curricular activities, suggested activities such as religious activities, meditation, and meditation attending the moral training camp and practicing moral reasoning, community service 
activities. 3) Being a good model for teachers, parents, administrators. 4) Using group processes influence of the group. 5) Role-playing 6) Environment that is conducive to moral development. It can be seen that moral development requires several methods how to create the realization of moral values that leads to a desirable attitude that will result in behave in the correct manner.

Development model for moral promotion activities of students for schools under the Primary Educational Service Area Office. It is the development of teaching and learning activities that teachers or teachers teach at the elementary school level, consisting of 1) curriculum education, 2) determination of learning objectives, 3) the lesson plan preparation, 4) the teaching and learning activities, 5) the evaluation and evaluation of the development of moral promotion activities. It is to promote the organization of teaching and learning activities, inserting morality and ethics of students, and organizing activities to promote goodness for students to have morality which the research results are consistent with "OBEC moral school project" as follows by adhering to five principles: sufficiency, gratitude, honesty responsibility moral ideology This is in line with the research of Pornnipa Channoi (2017) [8], on "The moral behavior development activity model of students in private higher education institutions according to the characteristics of Thai ideal graduates", the research found that factors affecting the moral instillation of students of private higher education institutions in Chiang Mai Province. The external factors mean higher than the internal ones. It is considered to be of the first importance to promote and cultivate. External factors include in education environment, the process of cultivating morality the students' family status and social environment, respectively, the moral behavior of students of private higher education institutions in Chiang Mai Province. Overall is high When considering the following aspects: Discipline, when the meal is finished, students will place their plates on the table at the university, be prepared and attend classes as scheduled. On accountability, students focus on public work before personal matters, completing assignments on time. Sacrifice Students will help friends who are struggling with their strength student abilities honesty.

Students attend classes every time, although sometimes teachers do not check their names. In terms of having a student culture, dress and have beautiful Thai manners have gratitude to their benefactors participate in activities related to Thai traditions, arts and culture and having professional ethics students perform their duties with responsibility, honesty, follow the rules organizational rules and models, activity models, moral behavior development of students of private higher education institutions in Chiang Mai Province. It is called "CAPPAE MODEL" with Principles, objectives, content, knowledge and practice, social system, support for learning is classified into instructional management is divided into 6 steps: 1) raising awareness $(\mathrm{A}), 2)$ providing knowledge and practice $(\mathrm{P}), 3)$ creating conceptualization (C), 4) developing desirable characteristics Purpose (P), 5) Evaluate progress (A), 6) Evaluate (E) Moral promotion activities divided into, 1) Morality related to living in society consists of honesty, Sacrifices and discipline, 2) Occupation according to code of conduct. The virtues that students must have are honesty, behaving according to professional ethics, emphasizing the results of using the moral behavior development activity model of students of private higher education institutions in Chiang Mai Province from observing behavior project evaluation. The self-reporting and assessments of the students' self-control showed that the students who were taught in order to develop a holistic moral behavior in three areas: behavior, mind and intelligence; and change for the better for both moral reasoning Attitudes towards moral behavior the format of moral promotion activities is very appropriate especially in the area of professional ethics responsibility and the sacrifice, respectively.

This may be because organizing activities is the policy of the university with the goal of developing all students to be complete including physical, mental, intellectual, knowledge, virtue, virtue and culture of living can live happily with other people. The learning activities that promote the development of moral behavior of the students were satisfied at a high level, especially the teaching management model that promotes moral development, be responsible for yourself and the public encourage students to be creative, thinking of solving problems in helping society more courage to express yourself, research results of moral reasoning of the students. Most of the students have the sixth stage of moral reasoning. Students have an average level of moral reasoning in the fifth stage, which is consistent with Kolberg's theory of moral development that people over 16 years of age have a higher level of moral development, the fifth and the third. This is the stage in which conflicts are settled. It is also consistent with Pranee Tantayanuputr (2008) [9], study of cognitive and logical reasoning. Moral values of the undergraduate students found that the moral cognitive mean of students in public and private universities. Most of them agree that the areas of responsibility, honesty, discipline, patience, justice, perseverance, and respect for the elders are at the level of gratitude and sacrifice. In level, should do especially for the SAVINGS AND SAVINGS Public university students agree that they should. The private sector thinks that this should be done especially when testing the mean hypothesis with tstatistic at the .05 significance level, it was found that the mean of moral knowledge and understanding of private university students was higher than that of the state. Analysis section compare the moral reasoning among public and private university students, overall, public university students had a fifth level mean of moral reasoning according to Kolberg's theoretical concept, that is, in principle, rational and considerate. The average level of moral reasoning is in the 4th level, that is, in the principle of fulfilling duties and order of society. When testing the mean hypothesis obtained with t- statistic at the .05 significance level, it was found that the moral reasoning mean had no difference in value at a similar level. It is in the principal stage, acts according to the duties and order of society, has reasons and takes into account the common interests. For comparative analysis of the moral reasoning of students in business and nonbusiness disciplines Overall, non-business students had an average of moral reasoning is in the fifth stage, that is, in principle, is rational and takes into account the common interests. For the average, the level of moral reasoning of business students is in the fourth stage, that is, in the principal stage of the function and order of society. When 
testing the mean hypothesis obtained with statistics at the .05 significance level, it was found that the moral reasoning mean had no difference in value. Students in both disciplines had moral reasoning at the same level. It is in the principal stage, acts according to the duties and order of society, has reasons and takes into account the common interests.

Development model for moral promotion activities of students to achieve results. There will be 3 main focus areas: 1) The number of students who have been developed to have more desirable behaviors in school, 2) More participation from the beginning is (1) the study of the curriculum, (2) the purpose of setting learning, (3) teaching plan, (4) teaching, (5) teaching activities, and 6) measuring and evaluating learning results 3) The school instills five virtues: sufficiency, gratitude, honesty, responsibility, and moral ideology. Using the development model for moral promotion activities of students which is related to the research of Prayoon Srikwanprachcha (2559) [10] has conducted research on "Development of a Moral DisciplineEnhancing Activity Model for Primary School Students", the experimental group students had morality of discipline significantly higher than the control group at the .01 level, have virtue of discipline in the experimental and follow-up periods were higher than the control group for experimental students. Moral of discipline higher after participating in activities than before participating in activities with statistical significance at .01 level and experimental group students. There is no difference in moral knowledge on discipline. From the test after the completion of the activities according to the pattern and passed 2 weeks and is consistent with the research of Praphairat Lamjai (2014) [11], on "Moral development model morality of secondary school students ", the research found the results of the study of basic information and guidelines for moral development of secondary school students found that the moral development of secondary school students developed 3 aspects, namely discipline, honesty and public mind. The moral development model for secondary school students consisted of 1) problem condition and necessity, 2) Model rationale, 3) Basic concept, 4) Objectives, 5) Model structure, 6) Development activities, 7) Media and learning resources, 8) Measurement and evaluation. For the results of the moral development model of the experiment, the secondary school students found that the students had a higher moral and moral behavior after the model than before the model was statistically significant at .05 level, and the evaluation of the moral development model of secondary school students. There was a high level of overall satisfaction.

\section{Recommendations}

\section{A. Recommendations for practice}

Research results on a model of activity development to promote students' morality in primary schools under the Office of Primary Education Service Areas, the results of the study were suggested as follows:

1. Sufficiency schools should train students in implementing royal ideas of sufficiency economy applied in teaching and learning and promoting the establishment of savings cooperatives within educational institutions to promote the savings of students.

2. Gratitude schools should regularly promote moralbuilding activities related to gratitude to their benefactors and should be organized into a moral camp with an emphasis on gratitude.

3. Integrity schools should promote honest conduct integrity is the key and should promote students' virtue, conduct with integrity, such as giving a diploma or scholarships.

4. Responsibility schools should always have adequate control over the compliance with the rules and regulations with campaigns to maintain order and discipline within the school and should provide opportunities to participate in expressing opinions about the school's discipline and discipline to make it more appropriate for students by adhering to democracy.

5. Ideology and morality schools should encourage students to know how to help those who are in constant distress, such as donating things to the needy, etc., and promote generosity and self-sacrifice for the common good, such as volunteering in public benefit projects.

\section{B. Recommendations for further research}

If further research is to be done on the development of student moral promotion activities, the researcher recommends conducting research in the following way.

1. Should study from schools that organize moral promotion activities that the same or different virtues were used from this research.

2. Should study the implementation of Buddhist principles used in conjunction with activities promoting morality in schools.

3. Should be studied in a research that narrows the scope of the research area, and should be defined as a specific area of study.

4. The research results obtained should be applied to schools or the next unit in order to consider the achievement in organizing activities for further moral promotion.

\section{Conclussion}

Development of a model of activity development to promote students' morality in primary schools under the Office of Primary Education Service Areas, all 5 areas consisted of 1) sufficiency, 2) appreciation, 3) honesty, 4) responsibility, and 5) ideology and morality as a whole at a high level, and at high level in all aspects, as for the development of model, development, moral promotion activities of students for schools under the Primary Education Service Area Office, it was found that the development model for moral promotion activities of students. For schools under the Primary Educational Service Area Office, it is the development of teaching and learning activities that teachers or teachers teach at the elementary school level, consisting of 1) curriculum education, 2) determination of learning objectives, 3) the lesson plan preparation, 4) the teaching and learning activities, 5) the evaluation and evaluation. The development of moral promotion activities. It is to promote the organization of teaching and learning activities, inserting morality and ethics of students, and organizing activities to 
promote goodness for students to have morality which the research results are consistent with "OBEC moral school project" as follows by adhering to five principles: sufficiency, gratitude, honesty responsibility moral ideology. For the presentation of the development model of student moral promotion activities (EASS Model) to achieve success, there will be 4 main focus points: 1. Ethic, promoting 5 virtues for students: 1) sufficiency, 2) gratitude, 3) honesty, 4) responsibility, 5) moral ideology 2. Activity Development of teaching and learning activities, namely 1) Curriculum study, 2) Determination of learning objectives, 3) Teaching plans, 4) Arranging activities for teaching and learning, and 5) measuring and evaluating learning results. 3. Support to support the development of moral promotion activities of students under the cooperation between the administrators, teachers, school directors, monks, parents and the community. 4. Student Students will benefit the most from the development of moral promotion activities of students. For schools under the Primary Educational Service Area Office considered to be a star in society because he will be those who have "Knowledge and virtue".

\section{References}

[1] Office of the Basic Education Commission. Learning reform process 2 nd edition, Bangkok: Office of the Basic Education Commission, 2010.

[2] Commission on Education, Religion, Arts and Culture. Upholding student morality and ethics, Bangkok: Press Office of the Senate Secretariat, 2007.

[3] Phra Phrom Bandit (Prayoon Dhammajitto), Direction of Thai education. 5th edition, Bangkok: Mahachulalongkornrajavidyalaya Printing House, 2013.

[4] Phramaha Likhit Rattanasiri, Morality and the development of students in the educational reform era. 2nd edition, Bangkok:

Mahachulalongkornrajavidyalaya

University, 2008.

[5] Office of the Basic Education Commission, Dhamma School, OBEC, Bangkok: Office of the Basic Education Commission, 2017.

[6] K. Chanywa, Narathiwat Primary Educational Service Area 1 ", Doctor of Philosophy Dissertation Education Administration Branch Graduate school North Bangkok University, 2017.
[7] N. Jaichalad, "Moral and Ethical Enhancement Model for Students of Thai Higher Education Institutions", Ph.D. Educational Administration Program, Graduate School, Naresuan University, 2010.

[8] P. Channoi, "Ethical Behavior Development Activity Model for Students in Private higher education institute according to the characteristics of Thai ideal graduates "Doctor of Doctoral Philosophy Dissertation in Educational Leadership and Human Resource Development, Graduate school Chiang Mai University, 2017.

[9] P. Tantayanuabutr, "Education of cognition and logical reasoning Ethics of Undergraduate Students ", Dissertation Doctor of Philosophy Department of Education, Faculty of Arts and Science Dhurakij Pundit University, 2008.

[10] P. Kwanprachcha, "Development of a Moral Discipline-Building Activity Model for Elementary school students Doctor of Philosophy, Doctor of Philosophy Department of Curriculum Research and Teaching, Faculty of Education, Sakon Nakhon Rajabhat University, 2016.

[11] P. Lamjai, "Moral development model Ethics for secondary school students ", Doctor of Education Dissertation Education Administration Branch Graduate School, University of Phayao, 2014. 